\title{
Concept of Ductility in Reinforced Concrete Design Explained in the Adotion of Eurocode 2 in Place of Bs 8110 in Malaysia
}

\author{
Jeffrey Chiang ${ }^{1}$
}

${ }^{1}$ Professor and Dean

Faculty of Engineeing \& the Built Environment, SEGi University, Kota Damansara, PJ, Selangor

${ }^{1}$ Vice-President

The Institution of Engineers, Malaysia (IEM)

Keywords: design concepts, comparison of standards, basis of design, concrete structures, ductility, strength

\begin{abstract}
The design of reinforced concrete structures requires a few criteria to be fulfilled, especially in Limit States Theory adopted by many international standards in structural design. Two key criteria are ultimate limit state and serviceability limit state. Both of these limit states have one common aspect which governs the whole concept of design especially in reinforced concrete design, which is the ductility requirement. The purpose of satisfying the ductility requirement is to ensure safety of users and occupants of the designed structure. In this paper, the ductility requirement is explained in the adoption of the Eurocode EC2 in place of BS8110. In order to have a smooth transition from BS8110 to EC2, the author would also like to introduce a unified approach for the analysis and design of concrete members in flexure by utilizing a unifying parameter q (combined reinforcing index). This would allow a design engineer to analyze and to design for normally reinforced, partially prestressed, and even fully prestressed concrete and composite sections. Through this approach, it is hoped that the Malaysian practicing structural engineers can make a smooth switchover to the use of Eurocode EC2 for reinforced concrete design.
\end{abstract}




\section{Introduction}

In 2003, The Institution of Engineers Malaysia recommended strongly through its Position Paper that, since UK is adopting Eurocode EC2 [1] in place of BS8110:1997 [2] by 2010, then it is advisable for Malaysia to follow suit. By mid-2009, the Technical Committee has completed the draft National Annexes for EC0, EC1 and EC2, and upon considering public comments received, they are published as Malaysian Standards MS EN Eurocode documents [3, 4, 5]. This is on the understanding that these new sets of Malaysian Standards will superceed the existing MS 1195:1991[6], which is essentially a full adoption of BS 8110:1985, which will be withdrawn by BSI in 2010 .

\section{Issues Faced By Malaysian Engineers In Adopting Eurocodes}

Besides having to grapple with the understanding and use of Eurocode EC2, designers will also have to make use or refer to two other suite of Eurocodes, viz, Eurocode EC0 (Basis of structural design) [7] and Eurocode EC1 (Actions on structures) [8]. Hence, this paper will give further insights into the various issues as identified in the three Eurocodes documents as mentioned. The ductility concept will also be explained in the use of the $k_{\mathrm{u}}$-factor as adopted by comparison in three different international standards.

\subsection{MS EN 1990:2010 National Annex for Eurocode ECO - Basis of Structural Design}

One of the initial issues faced by Malaysian practitioners is the use of terminology which are different from the British Standards. Terms like 'actions' is used in place of 'loads', and 'permanent and variable actions' replace the usual 'dead and live loads' respectively.

Another major hurdle that need to be tackled by Malaysian engineers is the use of cylindrical compressive strength in EC0 as opposed to the cube strength compressive strength test which are prescribed in BS8110.

The various load combinations recommended in EC0 is a vast change from BS8110 in terms o complexity and coverage. Nevertheless BSI has managed to influence CEN to modify the BS EN1992 version of 
the Eurocode EC2, by incorporating some of the common features of alternate floor load combinations in braced and unbraced frames, as found in BS8110. The equation for loading combination under ultimate limit state is quite complicated in EC0.

In contrast to the complicated load combination issues faced by Malaysian engineers in understanding EC2, the allocation of the uniformly distributed loads on braced and unbraced framed structures has been simplified by UK, as EC2 provisions have been modified somewhat (with UK's influence) to be in line with that of BS 8110 .

\subsection{MS EN 1991:2010 National Annex for Eurocode EC1 - Actions on structures: Part 1-1: General actions, densities, self-weight, imposed loads for buildings}

For MS EN 1991:2010 National Annex for EC1, a separate Editorial Group was formed out of the Technical Committee on EC2, to look into the adherence and conformity of EC0 and EC1 to EC2. There is a recommended change in the Malaysian National Annex for the imposed load by heavy vehicles (e.g. fire-fighting vehicles) in the vicinity of building structures.

This is found in Table NA.2.6 under Category G loading, where the BS National Annex recommended a load range of $30 \mathrm{kN}<$ gross weight of heavy vehicle $<160 \mathrm{kN}$. And this corresponded with a recommended UDL of $q_{k}=5 \mathrm{kPa}$ which is considered low by Malaysian practice. An UDL of not less than $10 \mathrm{kPa}$ would be more reasonable as the gross weight of fire and rescue vehicles used in Malaysia, and the maximum load can go as high as $180 \mathrm{kN}$.

Hence, the Committee has decided to revise Category $G$ loading (for fire and rescue vehicles) to a load range $30 \mathrm{kN}<$ gross weight $<200$ $\mathrm{kN}$; using $q_{k}=10 \mathrm{kN} / \mathrm{m}^{2}$, and $Q_{k}$ to be stated as "To be determined for specific use (e.g. fire rescue emergency purpose vehicles)".

\subsection{MS EN 1992:2010 National Annex for Eurocode EC2 - Design of concrete structures: Part 1-1: General rules and rules for for buildings}

It has to be noted that to date, the Malaysian standards writers have only looked into the Eurocode EC2 Part 1-1: General rules and rules for buildings. There are other parts that need to be adopted as well. But these will carried out as future works.

In using newly adopted standards for concrete design, it is envisaged that the practitioners will face major issues in understanding the 
methodologies in analysis and design of structural elements or components, be it beams, slabs or columns in a typical concrete structures. To that end, the authors would like to recommend the use of the unified approach for the analysis and design of concrete members in flexure by utilizing a unifying parameter $q$ (combined reinforcing index). This was first mooted by a noted researcher, Prof Naaman [9, 10, 11 and 12] and it was found to be applicable as well in this transitional stage. This would allow a design engineer to analyze and to design for normally reinforced, partially prestressed, and even fully prestressed concrete and composite sections.

This approach was also presented by Chiang \& Hee [13] at a Joint IABSE-fib Conference, held in Croatia in 2010.

Appendices A1 and A2 give more details on these aspects.

\section{Misconception Faced By Malaysian Engineers On Ductility Issue}

Malaysian structural engineers may be well-trained in structural analysis and design, but their concept of design tends to be lacking. For example, most engineers tend to think that a reinforced concrete structure can be made stronger or robust by adding more steel reinforcement particularly in the tension side of the structure. This is termed as over-reinforced, as opposed to over-design.

During the course of presenting the adoption of Eurocodes in roadshows throughout Malaysia, the author has come across a number of local engineers who do not grasp the concept of ductility in design especially in reinforced concrete design. They tend to place the strength or serviceability criteria as the objective in design, forgetting the over-riding requirement of ductility which has to be fulfilled first and foremost.

This was clearly stated in the published paper by Chiang [14] as follow:

"For an adequate seismic-resistant designed structure, the keyword that needs to be addressed is - ductility. The severity of damage and 
response of structures to earthquake can be clearly shown where ductility is a key factor."

The objective of design is to ensure that structures can demonstrate appreciable ductility in the event of impending disaster especially in cases of overloads, or in facing natural phenomenon such as earthquakes or severe wind forces. Reinforced concrete structures can be designed to three criteria, ie.

1. Over-reinforced section

2. Under-reinforced section

3. Balanced reinforced section

This is first year design concept learnt by all serious structural engineers at university, in which the above three criteria are governed by the $k_{\mathrm{u}}$-factor.

Should the calculated $k$-factor is less than the $k_{\mathrm{u}}$-factor, then the section is considered as under-reinforced, which is a desirable situation, since it means that the steel component in RC structures will fail first, and allows the structure to exhibit ductile characteristics, hence giving sufficient warning to the occupants of impending structure failure, if no corrective actions are taken.

On the other hand, if the calculated $k$-factor is more than the $k_{\mathrm{u}}$-factor, then the section is considered as over-reinforced, which simply means that the steel component in RC structures will not fail first, and it will cause the concrete portion to fail explosively in a brittle manner, hence not giving sufficient warning to the occupants and may cause loss of lives and property damages.

The balanced reinforced section is a rare occurrence, where the $k=k_{\mathrm{u}^{-}}$ factor, and in this instance both the concrete and the steel components theoretically fail simultaneously - which is also not a desirable situation.

As learned by design engineers in university, if the design is unavoidably at over-reinforced situation, this can be countered by adding compression steel reinforcement - which is supposed to reduce the $k$-value to less than the $k_{\mathrm{u}}$-factor, hence the designed structure is 
considered as having ductile characteristic under severe loading condition.

\section{Approach In Adopting Eurocode Ec2 In Comparison To Bs8110}

On the matter of design of beam sections, a comparison is made on the value used for $k_{u}$-factor, i.e. the proportion of concrete beam effective depth under compression, which is a measure of the beam ductility possessed:

\begin{tabular}{l|l|l}
\hline Standards & $\boldsymbol{k}_{\boldsymbol{u}}$ & \% balanced failure \\
\hline BS8110 & 0.50 & 79 \\
\hline AS3600 & 0.40 & 67 \\
\hline MS EN1992 & 0.60 & 94 \\
\hline
\end{tabular}

Table 1 - Comparison of standards on $k_{u}$-factor

So, the Eurocode EC 2 requirement for ductility is greater than the British Standards and the Australian Standards for concrete structures. In the next few sections, some examples will be presented on how the unified approach is used to analyse and design beams of different types or permutations. The figure in Appendix A1 illustrates how a partially prestressed beam section can be analysed in terms of its $q$ combined reinforcing index.

Appendix A1 also provides a detailed derivation of unified equations for analysis and design in flexural in accordance with MS EN 1992. In the figure shown in A1, the effective depth of the beam section can be calculated based on the various depths of the tension and compression steel reinforcement, and the prestressed tendon, multiplied with their respective forces exerted. Noting that $\gamma=0.8$ for $\gamma k_{u} d$, then a horizontal force equilibrium is carried out, from which the summation of forces can be separated out so that the concrete force portion will be equated to the summed of forces exerted by the various reinforcement and tendon, giving rise to,

$0.567 \gamma k_{u}=0.87 q_{p}+0.87 q_{s}-0.87 q^{\prime}{ }_{s}=q$ 
where the various " $q$-terms" used refer to the steel area or tendon area ratios, and the final $q$ at the end, is referred to as the combined reinforcing index. Other related derivation equations can be found in Appendix A1 for reference.

For MS EN 1992, as in all international codes of practice, beam sections must be designed to be ductile. Therefore the q values must be in the range of $0.272 \geq q \geq 0.056$. At a glance the comparison in design and analytical steps using the $q$-term, are shown for Eurocode EC2 and BS8110, in Tables 2 and 3 below.

\begin{tabular}{|c|c|}
\hline \\
\hline \multicolumn{2}{|c|}{$\begin{array}{l}\text { Initial data: } \\
\left.f_{c k}=\mathrm{C} 30 / 37 \text { (Note: } f_{c k}=30 \mathrm{MPa}, f_{c u}=37 \mathrm{MPa}\right) ; f_{y l, k}=460 \mathrm{Mpa} ; M_{E d}= \\
263.7 \mathrm{kNm} ; \\
b=300 \mathrm{~mm} ; \quad d=520 \mathrm{~mm} ; \quad K_{E C 2}=\frac{M_{E d}}{b d^{2} f_{c k}}=0.108: \quad \mathrm{K}_{\mathrm{BS} 8110}= \\
\frac{\mathrm{M}_{\mathrm{Ed}}}{\mathrm{bd}^{2} \mathrm{f}_{\mathrm{cu}}}=0.087\end{array}$} \\
\hline Eurocode EC2 & Output \\
\hline $\begin{array}{l}q=0.567\left[1-\sqrt{1-\frac{2 \mathrm{~K}}{0.567}}\right]=0.87 q_{s}=0.567 \gamma k_{u} d \quad[\gamma= \\
\left.0.8, k_{u}=0.60\right] \\
\text { The calculated } q=0.120 \quad<\text { which fits within } \\
\text { acceptable ductile range between }<0.272 \text { and } 0.056>\text {. } \\
\text { Hence, } q_{s}=\frac{q}{0.87}=0.137 \\
\text { which gives area of tension steel, } A_{s t}=\frac{q_{s} b d f_{c k}}{f_{y l, k}}=1393 \\
\mathrm{~mm}^{2}\end{array}$ & $A_{s t}=1393 \mathrm{~mm}^{2}$ \\
\hline BS 8110 & \\
\hline $\begin{array}{l}q=0.450\left[1-\sqrt{1-\frac{2 K}{0.45}}\right]=0.87 q_{s}=0.45 k_{u} d \quad[\gamma= \\
\left.0.9, k_{u}=0.50\right] \\
\text { The calculated } q=0.098 \quad<\text { which fits within } \\
\text { acceptable ductile range between }<0.202 \text { and } 0.045>\text {. }\end{array}$ & \\
\hline
\end{tabular}


Hence, $q_{s}=\frac{q}{0.87}=0.113$

which gives area of tension steel, $A_{s t}=\frac{q_{s} b d f_{c u}}{f_{y l, k}}=1417$ $A_{s t}=1417 \mathrm{~mm}^{2}$ $\mathrm{mm}^{2}$

Table 2 - Design comparison between EC2 and BS8110

\section{Initial data:}

$f_{c k}=\mathrm{C} 30 / 37$ (Note: $\left.f_{c k}=30 \mathrm{MPa}, f_{c u}=37 \mathrm{MPa}\right) ; \quad f_{y l, k}=460 \mathrm{Mpa} ; \quad A_{s l}$ $=1393 \mathrm{~mm}^{2}$

$b=300 \mathrm{~mm} ; \quad d=520 \mathrm{~mm}$

\begin{tabular}{|c|c|}
\hline Eurocode EC2 & Output \\
\hline $\begin{array}{l}q=0.567\left[1-\sqrt{1-\frac{2 K}{0.567}}\right]=0.87 q_{s}=0.567 k_{u} d \quad[\gamma= \\
\left.0.8, k_{u}=0.60\right] \\
\text { Now, the steel ratio } q_{s}=\frac{A_{s l} f_{y l, k}}{b d f_{c k}}=0.137 ; q=0.87 ; \\
q_{s}=0.119 \\
\text { Hence, } q=0.87 q_{s}=0.119 \text { which fits within } \\
\text { acceptable range between }<0.272 \text { and } 0.056>\text { for } \\
\text { ductility. } \\
K=\frac{M_{E d}}{b d^{2} f_{c k}}=q\left[1-\frac{0.5 q}{0.567}\right]=0.107 \text { which gives } \\
\text { moment capacity of beam, } M_{R d}=0.107 \times 300 \times 520^{2} \times \\
30 \times 10^{-6}=260.4 \mathrm{kNm}\end{array}$ & $\begin{array}{l}M_{R d}=260.4 \\
\mathrm{kNm}\end{array}$ \\
\hline BS 8110 & \\
\hline $\begin{array}{l}q=0.450\left[1-\sqrt{1-\frac{2 K}{0.45}}\right]=0.87 q_{s}=0.45 k_{u} d \quad[\gamma= \\
\left.0.9, k_{u}=0.50\right]\end{array}$ & \\
\hline Now, the steel ratio $q_{s}=\frac{A_{s l} f_{y l, k}}{b d f_{c u}}=0.111$ & \\
\hline $\begin{array}{l}\text { Hence, } q=0.87 q_{s}=0.097<\text { which fits within } \\
\text { acceptable range between } 0.202 \text { and } 0.045>\text { for }\end{array}$ & \\
\hline
\end{tabular}




\begin{tabular}{|l|l|}
\hline ductility. & \\
$K=\frac{M_{E d}}{b d^{2} f_{c u}}=q\left[1-\frac{0.5 q}{0.45}\right]=0.087 \quad$ which gives & \\
moment capacity of beam, $M_{R d}=0.087 \times 300 \times 520^{2}$ & \\
$\times 37 \times 10^{-6}=261.1 \mathrm{kNm}$ & $\begin{array}{l}M_{R d}= \\
\mathrm{kNm}\end{array}$ \\
& 261.1 \\
\hline
\end{tabular}

Table 3 - Analytical approach comparison between EC2 and BS8110

\section{Recommendations To Alleviate Problems And Issues Faced By Malaysian Engineers In Adopting Eurocode Ec2}

- Engineers in Malaysia has to accept the inevitable and be prepared to learn, understand and use new concepts and approach in design and analysis of structures.

- All private and public stakeholders in the construction industry, have to take the initiative to embrace and encourage the use of the new standards in practice.

- Universities may have to revamp their teaching syllabus to accommodate the switchover in concrete code.

- The concept of "Train the trainers" has to be implemented, so that lecturers in universities are taught the basic fundamentals of new standards to be adopted.

- The use of the unified approach in design and analysis of concrete structures is a innovative way to ensure a smooth transition in use of standards

- It is very important that the concept of ductility has to be instilled into all engineering students in university design courses, and also to be re-learned by practicing engineers in the field, if they had overlooked or underestimated its importance.

\section{Conclusion}

This paper has presented the problems and issues faced by Malaysian engineers in the impending switchover in use of standards for design of concrete structures, from the well-established BS8110 to MS EN 1992 Eurocode EC2 by 2010. Some background information leading up to the decision to adopt EC2 were also highlighted, as well as the 
process of implementation to be led by The Institution of Engineers, Malaysia (IEM). The use of the unified design and analytical approach was presented in both BS8110 and EC2, and it is proven that this will help somewhat to smoothen the switchover during the expected transitional period, prior to total adoption of EC2 in Malaysia. The importance of ductility in design is especially highlighted so that it is not to be misconstrued as not important in the design approach. This together with the various recommendations cited would go a long way to educate Malaysian engineers of new and advanced knowledge in design of concrete structures.

\section{References}

[1] BSI. 2004. BS EN 1992:2004. Design of concrete structures: London, UK.

[2] BSI. 1997. BS 8110-1:1997. Structural use of concrete: Code of practice for design and construction. London, UK

[3] DSM. 2010. National Annex to MS EN 1990:2010. Basis of structural design: KL, Malaysia.

[4] DSM. 2010. National Annex to MS EN 1991:2010. Action on structures: KL, Malaysia.

[5] DSM. 2010. National Annex to MS EN 1992:2010. Design of concrete structures: KL, Malaysia.

[6] BSI. 2002. EN 1990:2002. Basis of structural design: London, UK.

[7] SM. 1991. MS 1195:1991. Structural use of concrete: Code of practice for design and construction. KL, Malaysia.

[8] BSI. 2003. BS EN 1991:2003. Action on structures: London, UK.

[9] Naaman, A.E., Prestressed Concrete Analysis and Design Fundamentals, $2^{\text {nd }}$ Ed, Techno Press, 2004

[10] Naaman, A.E., Unified Design Recommendations for Reinforced, Prestressed, and Partially Prestressed Concrete Bending and Compression Members, ACI Structural Journal, Vol. 89, No. 2, March/April 1992, pp. 200-210.

[11] Naaman, A.E., Bending Strength Design of Prestressed and Partially Prestressed Concrete Members with the New AASHTO Code, Journal of Structural Engineering, ASCE, Vol.121, No. 6, June 1995, pp. 964-970.

[12] Naaman, A.E., Limits of Reinforcement in the 2002 ACI Code: Transition, Flaws, Solution, ACI Structural Journal, Vol. 
101, No. 2, March-April, 2004, pp. 209-218. See also discussion and closure in ACI Structural Journal, Jan.-Feb. 2005.

[13] Chiang, C.L. \& Hee, M.C. The Issues Faced by Malaysian Engineers in Adopting Eurocode EC2 by 2010, Joint IABSE-fib Conference on Codes in Structural Engineering: Development and Needs for International Practice Proceedings, Dubrovnik, Croatia, 3-5 May 2010.

[14] Chiang, C.L. Continuing Development of Seismic Actions Design Standard and Implications to Engineering and Architectural Practices in Malaysia. Journal of Engineering \& Technological Advancces, Vol 1 No 1 ISSN 2550-1437, Jan 2016, SEGi University, pp. 27-46.

\section{Acknowledgment}

The authors would like to acknowledge the contributions of members of the Technical Committee formed by The Institution of Engineers, Malaysia to draft the National Annex for the now published Malaysian Standards MS EN1992:2010 for design of concrete structures. Their hard work and dedication have been instrumental in getting the Standards drafting work completed, and in making possible this paper submitted for publication.

\section{Notation}
$A_{\mathrm{sl}}=$ area of tensile reinforcing $\gamma_{\mathrm{s}}=1.15$ partial factor of steel reinforcing or prestressing steel

$\mathrm{A}^{\prime}{ }_{\mathrm{sl}}=$ area of compression $\gamma_{\mathrm{c}}=1.5$ partial factor for reinforcing steel concrete

$A_{p s}=$ area of prestressing steel $f_{c u}=$ characteristic compressive cube strength of concrete at 28 days

$\mathrm{b}=$ width of beam $\quad \mathrm{f}_{\mathrm{ck}}=$ characteristic compressive cylinder strength of concrete at 28 days 
$\mathrm{d}=$ hydbrid effective depth $\mathrm{f}_{\mathrm{y}, \mathrm{k}}$ characteristic yield strength between reinforcing and $=$ of reinforcement prestressing steel

$\mathrm{d}^{\prime}=$ compression steel depth $\quad \mathrm{E}_{\mathrm{cm}} \quad$ secant modulus of elasticity $=$ of concrete

$\mathrm{d}_{\mathrm{p}}=$ depth of prestressing $\mathrm{F}_{\mathrm{s}}$ characteristic tensile steel $=$ strength of prestressing steel

$d_{s}=$ depth of reinforcing steel $M_{E d}$ design value of the applied $=\quad$ internal bending moment

$E_{p}=$ design value of modulus $M_{R d}$ design moment resistance of of elasticity of $=$ the section

prestressing steel

$E_{s}=$ design value of modulus $q=$ combined reinforcing index of elasticity of

reinforcing steel

$\mathrm{k}_{\mathrm{u}} \mathrm{d}=$ depth to the neutral axis $\quad \mathrm{q}_{\mathrm{p}}=$ prestressing index

$\alpha_{c c}=0.85$ is the coefficient $\mathrm{q}_{\mathrm{s}}=$ tension reinforcing index taking account of long term effects on the compressive strength and of unfavourable effects resulting from the way the load is applied
$\eta=1.0$ for $\mathrm{f}_{\mathrm{ck}} \leq 50 \mathrm{MPa} \quad \mathrm{q}_{\mathrm{s}}=$ compression reinforcing index

$\gamma=\mathrm{a}$ factor defining the effective height of the compression zone of the equivalent concrete stress block 


\section{Appendix A}

\section{Unified approach to design to MS EN 1992-1-1:2010 refer to as EC2}

\section{Basic parameters to be used for analysis and design:}

- The 0.85 factor allows the difference between the bending strength and the cylinder crushing strength of the concrete.

- The partial safety factor $\gamma_{c}$ for concrete is 1.5 and $\gamma_{s}$ for steel is 1.15 .

- The ultimate strain of concrete is 0.0035 and the yield strain of reinforcing steel is 0.0020 for $f_{y, k}=460 \mathrm{MPa}$.

\section{A1 Derivation of unified equations for analysis and design in flexural in accordance with MS EN1992}

Considering horizontal equilibrium:

$0.567 \mathrm{f}_{\mathrm{ck}} b \gamma \mathrm{k}_{\mathrm{u}} \mathrm{d}=0.87 \mathrm{~A}_{\mathrm{ps}} \mathrm{f}_{\mathrm{ps}}+0.87 \mathrm{f}_{\mathrm{yl}, \mathrm{k}}-0.87 \mathrm{f}_{\mathrm{yl}, \mathrm{k}} \mathrm{A}_{\mathrm{sl}}$

Divide both sides by bdf $f_{\text {ck }}$ and note that $d$ is the hybrid centroid not $d_{s}$ or $d_{p}$ $0.567 f_{\text {ck }} b \gamma k_{\mathrm{u}} \mathrm{d} / \mathrm{bdf}_{\mathrm{ck}}=0.87 \mathrm{~A}_{\mathrm{ps}} \mathrm{f}_{\mathrm{ps}} / \mathrm{bdf}_{\mathrm{ck}}+0.87 \mathrm{f}_{\mathrm{yl}, \mathrm{k}} / \mathrm{bdf} \mathrm{f}_{\mathrm{ck}}-0.87 \mathrm{f}_{\mathrm{yl}, \mathrm{k}} \mathrm{A}^{\prime} \mathrm{sl} / \mathrm{bdf} \mathrm{f}_{\mathrm{ck}}$ $0.567 \gamma k_{u}=0.87 q_{p}+0.87 q_{s}-0.87 q{ }^{\prime} s=q$

(A1-1)

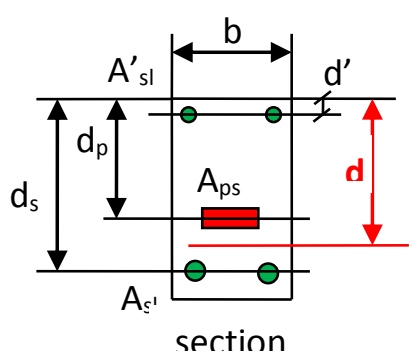

$$
d=\frac{0.87\left(A_{p s} f_{p s}\right) d_{p}+0.87\left(A_{s l} f_{y l, k}\right) d_{s}}{0.87 A_{p s} f_{p s}+0.87 A_{s l} f_{y l, k}}
$$

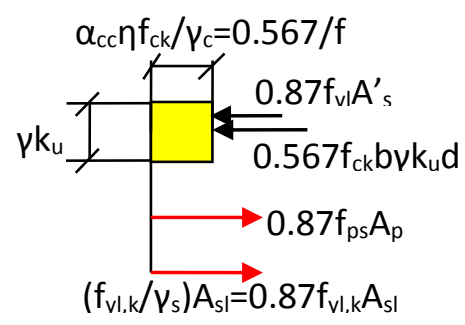

stress

$f_{p s}=\frac{F_{s}^{\prime}\left[1-0.5 A_{p s} F_{s}^{\prime}\right]}{b d_{p} f_{c k}}$

$q$ is the combined reinforcing index. It is a unifying parameter for reinforced, prestressed and partially prestressed sections.

$\mathrm{q}_{\mathrm{p}}=\mathrm{A}_{\mathrm{ps}} \mathrm{f}_{\mathrm{ps}} / \mathrm{bdf}_{\mathrm{ck}}$ is the prestressing index $\mathrm{q}_{\mathrm{s}}=\mathrm{f}_{\mathrm{yl}, \mathrm{k}} / \mathrm{bdf}_{\mathrm{ck}}$ is the tensioned reinforcing index and $\mathrm{q}_{\mathrm{s}}=\mathrm{f}_{\mathrm{yl}, \mathrm{k}} \mathrm{A}_{\mathrm{s}}{ }_{\mathrm{s}} / \mathrm{bdf}_{\mathrm{ck}}$ is the compression reinforcing index

$q=($ compression force in concrete $) / b d f_{c k}=($ net force in steel $) / b d f_{c k}$

Taking $\Sigma \mathrm{M}=0$ with $\mathrm{d}$ as lever arm:

$\mathrm{M}_{\mathrm{Ed}}=0.567 \mathrm{f}_{\mathrm{ck}} \mathrm{b} \gamma \mathrm{k}_{\mathrm{u}} \mathrm{d}\left(\mathrm{d}-\gamma \mathrm{k}_{\mathrm{u}} \mathrm{d} / 2\right)+0.87 \mathrm{f}_{\mathrm{yl}, \mathrm{k}} \mathrm{A}^{\prime}{ }_{\mathrm{sl}}\left(\mathrm{d}^{-} \mathrm{d}^{\prime}\right)$

(A1-2) 
Substituting equatiton (A3-1) into equation (A3-2) and noting $0.567 \mathrm{f}_{\mathrm{ck}} \mathrm{b} \gamma \mathrm{k}_{\mathrm{u}} \mathrm{d} /$ $\mathrm{bdf}_{\mathrm{ck}}=\mathrm{q}$

Gives $0.567 \gamma \mathrm{k}_{\mathrm{u}}=\mathrm{q}$ and transforming $\gamma \mathrm{k}_{\mathrm{u}}=\mathrm{q} / 0.567$, hence equation (A3-1) becomes

$$
\begin{aligned}
\mathrm{M}_{\mathrm{Ed}} & =\operatorname{bdf}_{\mathrm{ck}} \mathrm{qd}\left(1-0.5 \gamma \mathrm{k}_{\mathrm{u}}\right)+0.87 \mathrm{f}_{\mathrm{yl}, \mathrm{k}}\left(\mathrm{d}-\mathrm{d}^{\prime}\right) \\
& =\mathrm{bd}^{2} \mathrm{f}_{\mathrm{ck}} \mathrm{q}(1-0.5 \mathrm{q} / 0.567)+0.87 \mathrm{f}_{\mathrm{yl}, \mathrm{k}}\left(\mathrm{d}-\mathrm{d}^{\prime}\right)
\end{aligned}
$$

dropping the compression reinforcing term and solved for $\mathrm{q}$, hence $K=\frac{M_{E d}}{b d^{2} f_{c k}}=q\left[1-\frac{0.5 q}{0.567}\right]$ is a quadratic equation in terms of $\mathrm{q}$, $q=0.567\left[1-\sqrt{1-\frac{2 K}{0.567}}\right]=0.87 q_{p}+0.87 q_{s}-0.87 q^{\prime}{ }_{s}=0.567 \gamma k_{u}$

For prestressed ultimate limit state

$q=0.567\left[1-\sqrt{1-\frac{2 K}{0.567}}\right]=0.87 q_{p}$

$f_{p s}=\frac{F_{S}^{\prime}\left[1-0.5 A_{p s} F_{S}^{\prime}\right]}{b d_{p} f_{c k}}$

$q_{p}=\frac{A_{p s} f_{p s}}{b d f_{c k}}$

Substitute $\mathrm{f}_{\mathrm{ps}}$ in equation (A3-3) into $\mathrm{q}_{\mathrm{p}}$ in equation (A3-4) and let $q_{p}^{*}=$ $\frac{A_{p s} F_{s}^{\prime}}{b d_{p} f_{c k}}$ will results in $\mathrm{q}_{\mathrm{p}}=\mathrm{q}^{*} \mathrm{p}\left[1-0.5 \mathrm{q}_{\mathrm{p}}^{*}\right]$ and solve for quadratic equation in $\mathrm{q}^{*} \mathrm{p}$. Hence,

$q_{p}^{*}=\left[1-\sqrt{1-2 q_{p}}\right]=\frac{A_{p s} F_{s}^{\prime}}{b d_{p} f_{c k}}$

$A_{p s}=\frac{q_{p}^{*} b d_{p} f_{c k}}{F_{s}^{\prime}}$ is computed, and similarly

$$
f_{p s}=\frac{F_{s}^{\prime}\left[1-0.5 A_{p s} F_{s}^{\prime}\right]}{b d_{p} f_{c k}}
$$

\section{A2 Ductility flexural failure in accordance to MS EN1992}

EC2 imposed $k_{u}=0.60$ for a beam section to possess maximum ductility.

$$
q=0.567\left[1-\sqrt{1-\frac{2 K}{0.567}}\right]=0.87 q_{p}+0.87 q_{s}-0.87 q^{\prime}{ }_{s}=0.567 \gamma k_{u}
$$

As $\gamma=0.8$, hence $q_{\max }=0.567 \times 0.8 \times 0.60=0.272$

And for $q_{\min }$ condition, it is obtained from $z=d-\gamma k_{u}(1 / 2 d)=d\left[1-0.8 k_{u}(1 / 2)\right]=$ $0.95 d$

Therefore $k_{u}=0.125$ which will give $q_{\min }=0.567 \times 0.8 \times 0.125=0.056$ 